УДК 34.01

DOI 10.52575/2712-746X-2021-46-2-353-360

\title{
Разграничение вопросов факта и права: сравнительно-правовое исследование
}

\author{
Куксин И.Н., Зеленин Н.Ю. \\ Московский городской педагогический университет, \\ Россия, 129226, г. Москва, 2-ой Сельскохозяйственный проезд, д. 4, к. 1 \\ E-mail: proffKuk-1944@yandex.ru
}

\begin{abstract}
Аннотация. Идея разграничения вопросов факта и права в западной доктрине на протяжении веков детальнейшим образом исследовалась не только правоведами, но и правоприменителями, в частности судами высоких инстанций. Это связано с тем, что вопросы о фактических обстоятельствах в этой правовой системе традиционно разрешались присяжными, тогда как вопросы права относились к компетенции судей. Авторы исходят из того, что изучение сущности разграничения вопросов факта и права - необходимый элемент формирования современного и логичного профессионального правопонимания, поскольку проблемы и споры по этой теме остаются актуальными как в части конкретного правоприменения, так и в части абстрактного понимания сущности исследуемых явлений. В статье дана краткая сравнительно-правовая характеристика примеров использования концепта разграничения вопросов факта и права в различных правопорядках.
\end{abstract}

Keywords: вопросы факта и права, пределы пересмотра судебных решений, иностранное право, преюдиция.

Для цитирования: Куксин И.Н., Зеленин Н.Ю. 2021. В Разграничение вопросов факта и права: сравнительно-правовое исследование. NOMOTHETIKA: Философия. Социология. Право. 46 (2): 353-360. DOI 10.52575/2712-746X-2021-46-2-353-360

\section{Distinguishing issues of fact and law: a comparative legal study}

\author{
Ivan N. Kuksin, Nikita Y. Zelenin \\ Moscow City Pedagogical University, \\ 4, building 1 2nd Sel'skokhozyaistvennyi passage, 129226, Moscow, Russian Federation \\ E-mail: proffKuk-1944@yandex.ru
}

\begin{abstract}
The idea of distinguishing between questions of fact and law in Western doctrine has been studied in great detail for centuries not only by legal scholars, but also by law enforcement officials, in particular by high courts. This is due to the fact that questions of factual circumstances in this legal system were traditionally decided by juries, while questions of law were the responsibility of judges. The authors proceed from the fact that the study of the essence of the differentiation of issues of fact and law is a necessary element of the formation of a modern and logical professional legal understanding, since problems and disputes on this topic remain relevant, both in terms of specific law enforcement and in terms of an abstract understanding of the essence of the phenomena under study. The article provides a brief comparative legal description of examples of the use of the concept of distinguishing issues of fact and law in various legal systems.
\end{abstract}

Keywords: questions of fact and law, limits of judicial review, foreign law, prejudice.

For citation: Kuksin I.N., Zelenin N.Yu. 2021. Distinguishing issues of fact and law: a comparative legal study. NOMOTHETIKA: Philosophy. Sociology. Law series. 46 (2): 353-360 (in Russian). DOI 10.52575/2712-746X-2021-46-2-353-360 


\section{Введение}

Отечественная правовая наука многие годы отличается фундаментальным подходом к изучению права. Анализ и изучение наиболее общих закономерностей и тенденций происхождения, развития и функционирования государства и права в их постоянном взаимодействии - одно из значимых для отечественной юриспруденции направлений. В то же время, по мнению авторов, имеется достаточно условий, чтобы констатировать некоторую степень разобщенности фундаментальной юридической науки и правоприменительной практики в современной России. Будучи наследником как имперской, так и советской юриспруденции, отечественный правовой порядок динамично изменяется и вырабатывает свои собственные черты, что позволяет воспринимать его как молодую правовую систему. В силу этого возникает потребность в изучении некоторых правовых проблем путем перехода от частного к общему, от отраслевого знания к общетеоретическому, позволяющему разрабатывать удобные и практически применимые алгоритмы, которые могут быть восприняты в правоприменении.

В этой связи перспективными представляются компаративистские исследования как внутренне-исторические, так и с учетом опыта зарубежных коллег. Восприятие удачных научных и практических решений, их теоретическое осмысление и инкорпорирование в профессиональную деятельность - комплексная работа, позволяющая обращаться к юридическим механизмам как на уровне теоретической абстракции, так и в контексте реализации права.

\section{Концепт разграничения вопросов факта и права}

Одним из перспективных инструментов такого развития может быть осмысление концепта разграничения вопросов факта и права.

Концепт разграничения вопросов факта и права (law-fact distinction) - правовая идея, конструкция, тесно связанная с историей суда присяжных и на протяжении веков разрабатываемая в англо-американской юриспруденции. Однако, будучи рожденной в английском праве, это концепция оказала влияние на современное содержание процессуальных правил любой в той или иной степени развитой правовой системы.

Как было отмечено, осознанное и институциональное разграничение между вопросами факта (issues of fact) и вопросами права (issues of law) тесно связано с историей суда присяжных в Англии. Именно в рамках возникновения и развития этого института происходило концептуальное разграничение исследуемых понятий. Указанное положение объективно связано с тем, что вопросы о фактических обстоятельствах в этой правовой системе традиционно разрешались присяжными, тогда как вопросы права относились к компетенции судей.

Четкое и широко известное правоведам разграничение исследуемых понятий прослеживается к середине XVI века и связано с работами Э. Кока, самого известного и выдающегося правоведа своей эпохи и одного из самых известных юристов всех времен, с деятельностью которого связывают фактическое создание системы общего права [Weiner, 1966, с. 1867]. Обсуждаемая проблема была одной из его излюбленных тем. Он в своих работах, основываясь на известной латинской максиме, утверждал, что самый обычный метод разрешения вопросов факта - двенадцатью такими мужчинами, так как "ad questionem facti non respondent judices, ad questionem juris non respondent juratores" (вопросы факта не решают судьи, вопросы права не решают присяжные) [Coke, 1832, p. 155]. Такое разделение известно и современному российскому праву, и закреплено оно в положениях Уголовнопроцессуального кодекса РФ (ст. 299 «Вопросы, разрешаемые судом» и ст. 334 «Полномочия судьи и присяжных заседателей» $\left.{ }^{1}\right)$.

\footnotetext{
${ }^{1}$ Уголовно-процессуальный кодекс Российской Федерации от 18.12.2001 № 174-Ф3 (ред. от 05.04.2021 с изм. от 13.04.2021) // СЗ РФ. 2001. № 52 (ч. І). Ст. 4921; 2021. № 15 (Часть І). Ст. 2434.
} 
В начале XXI века суд с участием присяжных заседателей не утратил своей значимости и продолжает действовать во многих государствах: в свыше 20 странах общего права и в 20 зависимых от них территорий; в более 15 странах, принадлежащих к романо-германской правовой семье, двух скандинавских государства и ряде стран со смешанной правовой системой [Попаденко, Красильникова, 2019, с. 16].

Однако концепт, появившийся в связи с фактоустановительной функцией присяжных, не ограничивается пределами этого института. Помимо названного, он проявляется в различных сферах:

\section{- Правила пересмотра судебных постановлений.}

В России суды кассационных инстанций (в отличие от апелляционного производства) по общему правилу не вправе переустанавливать фактические обстоятельства, то есть проверяют ошибки в вопросах права, но не вопросах факта. Подобные правила относятся к любой из процессуальных отраслей и закреплены, например, в ч. 1, 3 ст. 286, п. 2 ч. 1 ст. 287, ч. 2 ст. 287 Арбитражного процессуального кодекса РФ $\Phi^{1}$; ч. 1 ст. 379.6, ч. 1 ст. 379.7, ч. 3 ст. 390 Гражданского процессуального кодекса РФ $\Phi^{2}$; п. 1 ст. 389.15 , п. 1 ст. 389.16 и ч. 1 ст. 401.15 Уголовно-процессуального кодекса РФ.

Таким образом, российский законодатель на нормативном уровне ограничивает полномочия высоких судов в вопросах установления фактических обстоятельств дела.

В иных правопорядках действует похожие правила. Например, в американской судебной системе вопросы факта по существу разрешаются судьями первой инстанции либо присяжными. К установленным таким образом фактам судья первой инстанции (trial judge) применяет нормы статутного и прецедентного права. Апелляционный суд по общему правилу исправляет ошибки нижестоящих судов в вопросах права [Будылин, 2014, с. 86]. Другим образом определить вопрос факта апелляционный суд может лишь тогда, когда нижестоящим судом он разрешен очевидным образом необоснованно, то есть имеется явная ошибка ${ }^{3}$. Логика в том, что явная и очевидная ошибка в разрешении вопроса факта является по своей сути нарушением требования права.

При этом важной отличительной особенностью правовой системы США является наличие так называемых стандартов пересмотра судебных решений (standard of review). Так, при проведении апелляционного судопроизводства к вопросам факта и права применяются различные стандарты пересмотра, то есть некоторые правила, устанавливающие пределы вмешательства апелляционной коллегии в усмотрение нижестоящего судьи, степень почтительности (deference) к его выводам.

Большинство судов при пересмотре используют четыре основных стандарта: de novo (заново, без учета выводов нижестоящего суда - обычно применим к вопросам права), clear error (явная ошибка, как мы указывали выше, применим наиболее часто для вопросов факта), substantial evidence (существенное доказательство - стандарт, применяемый к вердикту присяжных, который подлежит пересмотру тогда и только тогда, когда он вообще не подкреплен сколько-нибудь существенными доказательствами), abuse of discretion (специальный стандарт, который можно перевести как злоупотребление усмотрением; такой стандарт применяется, когда процессуальная оценка фактов судов первой инстанции совершена произвольно и ни на чем не основана, например, необоснованное признание доказательства неотносимым или недопустимым) [Casey, Camara, Wright, 2001, с. 279-384].

${ }^{1}$ Арбитражный процессуальный кодекс Российской Федерации от 24.07.2002 № 95-Ф3 (ред. от 08.12.2020) // СЗ РФ. 2002. № 30. Ст. 3012; 2020. № 50 (часть III). Ст. 8073.

${ }^{2}$ Гражданский процессуальный кодекс Российской Федерации от 14.11.2002 № 138-ФЗ (ред. от 08.12.2020 с изм. от 02.03.2021) // СЗ РФ. 2002. № 46. Ст. 4532; 2020. № 50 (часть III). Ст. 8073.

${ }^{3}$ Federal Rules of Civil Procedure. Rule 52(a). 
Таким образом, при наличии некоторых процессуальных различий, обусловленных иной структурой судебной системы, по своей сути сравниваемые правопорядки подчинены единому принципу, в соответствии с которым вопросы факта и права разграничиваются, а высокие суды пересматривают дела в части ошибок в разрешении вопросов права, но не пересматривают установленные фактические обстоятельства, если только не имеется явной ошибки или нарушений права в части процедуры установления и разрешения вопросов факта.

\section{- Вопросы установления содержсания иностранного права.}

В отечественной правовой науке первой половины XX века отсутствовало единое мнение относительно квалификации иностранного права и обязанности установления его содержания. Одни ученые признавали, что суд должен устанавливать содержание иностранного права ex officio [Яблочков, 1909], некоторые другие утверждали, что к иностранному праву и его содержанию нужно относится как к фактическому обстоятельству [Казанский, 1902].

Сегодня иностранное право в правовой науке России вполне однозначно трактуется как право, обязанность по установлению содержания которого по общему правилу возложена на суд, которому стороны вправе оказывать содействие. Суд должен применять иностранное право именно как правовые нормы и в соответствии с духом той правовой системы, частью которой они являются [Абова, Богуславский, Светланов, 2005, с. 309].

Отношение иностранных правопорядков к вопросам применения нормы иностранного права как факта или как права существенно отличается не только в разрезе правовых семей, но даже в пределах семьи общего права.

В Англии формирование традиционного подхода к вопросам иностранного права восходит к XVIII веку [Hausmann, 2008]. Такой подход применяется и сегодня: в Англии положения иностранного права являются «вопросом факта» и подлежат доказыванию сторонами [O’Brien, 1999, с. 145].

Подобным образом иностранное право квалифицировалось в правовой системе Соединенных Штатов Америки. Однако принцип квалификации иностранного права в качестве вопросов факта и соответственно определения того, что в судебном разбирательстве его содержание должно быть доказано сторонами, в законодательстве и практике США трансформировался и приобрел многие черты континентального подхода. В соответствии с ним содержание нормы иностранного права рассматривается в качестве правового вопроса. Так, в 1960-х годах на федеральном, а затем и региональном уровнях отказались от этого традиционного английского правила, объявив положения иностранного права «вопросом права» [Michalski, 2011].

Что касается правопорядков семьи романо-германского права, то, например, в правовой доктрине Германии признается, что содержание действующих в другом государстве норм требует доказывания только в том случае, если оно не может быть известно суду. Кроме того, при установлении содержания иностранного права немецкие суды не ограничены представленными сторонами доказательствами [Елисеев, 2004, с. 31].

Основываясь на сказанном, можно утверждать, что квалификация иностранного права - это теоретическое осмысление сущности иностранного права при его применении в стране суда с точки зрения его отнесения к правовой категории или к фактическому обстоятельству, в зависимости от которого определяется субъект доказывания (установления содержания) права.

\section{- Предель преюдициальности судебных рещений.}

Отделение вопросов факта от вопросов права имеет значение для преюдициальности судебных актов в условиях процессуальных ограничений деятельности публичных властных субъектов [Макогон 2013, 2014, 2017].

Российский правоприменитель, используя преюдицию, обычно обращается к двум наборам статей для правового обоснования. Во-первых, это общие положения-принципы об обязательности судебных актов: ч. 2 ст. 13 Гражданского процессуального кодекса РФ, 
ч. 1 ст. 16 Арбитражного процессуального кодекса РФ, ст. 16 Кодекса административного судопроизводства РФ ${ }^{1}$, ст. 392 Уголовно-процессуального права РФ. Во-вторых, используются специальные нормы об освобождении от доказывания: чч. 2-4 ст. 69 Арбитражного процессуального кодекса РФ, чч. 2-4 ст. 61 Гражданского процессуального кодекса РФ, чч. 2-3 ст. 64 Кодекса административного судопроизводства РФ, ст. 90 Уголовно-процессуального права РФ. При применении указанных положений судами используется один и тот же набор терминов - обязательность и преюдиция.

Оба набора статей обосновывают недопустимость пересмотра установленных иным судом обстоятельств, связаны с принципом правовой определенности. Однако представляется, что в сопоставимых наборах идет речь о разных проявлениях обязательности судебных актов. Так, в общих положениях (ч. 1 ст. 16 Арбитражного процессуального кодекса РФ, ч. 2 ст. 13 Гражданского процессуального кодекса РФ, ст. 16 Кодекса административного судопроизводства РФ, ст. 392 Уголовно-процессуального кодекса РФ) говорится именно о свойстве обязательности судебного акта, свойстве не персонифицированном. Вспоминая теоретическую классификацию М.А. Гурвича, можно говорить о положительной стороне преюдиции [Гурвич, 1976, с. 161-162]. Это свойство основано на принципе правовой определенности и заключается в обязанности неустановленного круга лица (в том числе государственных органов) сообразовывать свое поведение с судебным актом до той степени, покуда он не затрагивает их субъективные права и законные интересы. В ином случае такие лица приобретают право на самостоятельное участие в процессе. Объективные пределы общей обязательности не ограничиваются фактическими обстоятельствами, но структурно ограничены исключительно резолютивной частью судебного акта.

Говоря о положениях разделов о доказывании (чч. 2-4 ст. 69 Арбитражного процессуального кодекса РФ, чч. 2-4 ст. 61 Гражданского процессуального кодекса РФ, чч. 2-3 ст. 64 Кодекса административного судопроизводства РФ, ст. 90 Уголовно-процессуального кодекса РФ), мы подразумеваем собственно преюдицию, обязательно обладающую субъективным пределами и проявляющуюся только по вопросам факта (установленным обстоятельствам). Структурно источником преюдиции наиболее часто будет выступать мотивировочная часть судебного акта, поскольку именно там должны устанавливаться и определяться фактические обстоятельства.

По мнению авторов, несмотря на то, что отечественное право традиционно имеет более тесную связь с романо-германской семьей, правила преюдиции, определенные в российском законе, более походят на англо-американские.

Преюдиция в странах общего права тесно связана с правилами доказывания. Общее правило преюдициальности носит название res judicata (иногда его называют res judicata в широком смысле). Доктрина res judicata (в широком смысле) распадается на две составляющие: Claim preclusion (запрет на иск). Это относится к судебному решению в целом и означает запрет на рассмотрение споров между теми же лицами по тем же основаниям, фактически является полным аналогом известного нам свойства исключительности судебного решения. Issue preclusion - эта доктрина относится к отдельным вопросам факта (issue), разрешенным судами ранее. Нередко можно увидеть аналогичный термин: «estoppel by judgment» [Friedenthal, Kane, Miller, 2005, c. 645-646].

Сравнивая issue preclusion c claim preclusion, можно говорить, что одна одновременно и шире, и уже другой. Шире, поскольку issue preclusion применяется не только по тождественным искам, но и по иным делам, в то время как claim preclusion (исключительно) касается только одинаковых дел. Более узким issue preclusion по отношению к claim preclusion является потому, что оно касается только вопросов факта и не предрешает вопросы права [Smith, 2006, с. 43].

${ }^{1}$ Кодекс административного судопроизводства Российской Федерации от 08.03.2015 № 21ФЗ (ред. от 08.12.2020) // СЗ РФ. 2015. № 10. Ст. 1391; 2020. № 50 (часть ІІІ). Ст. 8073. 
По нашему мнению, именно доктрина issue preclusion наиболее похожа на установленные российским законодателем преюдициальные правила (ст. 69 Арбитражного процессуального кодекса РФ, ст. 61 Гражданского процессуального кодекса РФ, ст. 64 Кодекса административного судопроизводства РФ, ст. 90 Уголовно-процессуального кодекса РФ).

Таким образом, говоря о преюдиции, следует различать преюдициальное значение судебного решения в целом, с одной стороны, и отдельных установленных им фактов и высказанных в нем правовых позиций, с другой.

Различие между объективными пределами обязательности и преюдициальности (преюдиция только по вопросам факта; обязательность по всему существу вопросов, связанных с резолюцией судебного акта) как раз и обосновывает связь между этим институтом и концептом разграничения вопросов факта и права. Правильно определить объективные пределы преюдиции невозможно без понимания грани между правовым выводом и выводом об установленном фактическом обстоятельстве. Сегодня суды нередко допускают терминологическую неточность, называя нефактические выводы обязательными или преюдициальными, одновременно разрабатывая позицию, при которой признается, что преюдиция распространяется только на факты, но не их правовые оценки. Например, Судебная коллегия по гражданским делам Верховного Суда Российской Федерации распространяет пределы преюдициальности судебного решения на выводы суда о правоотношениях: лицо, ранее участвующее в деле о взыскании задолженности, не вправе оспаривать в другом гражданском процессе установленные судом факты, в частности факт прекращения поручительства $^{1}$. Верховный Суд ошибочно, по мнению авторов, называет правовой вывод о прекращении поручительства фактом (это определенно является вопросом права), однако указанное само по себе не влияет на существо и правильность принятого решения.

\section{Заключение}

Идея разграничения вопросов факта и права существует в сознании юристов разных правовых систем. Это общеправовой принцип, реципированный правовым сознанием ученых и практиков всего мира. Разграничение вопросов факта и права с той или иной степенью осознанности проявляется как в отечественном законодательстве, так и в праве иностранных государств. Изучаемая концепция непосредственно связана с практикой правоприменения. Она объективно проявляется в деятельности судов, нередко упоминается в текстах судебных решений. При этом обнаруживается, что с позиции теоретического осмысления названная тема практически мало исследована, в частности, в отечественной доктрине. С одной стороны, указанное обуславливается функциональным подходом в преодолении возникающих сложностей и вопросов, однако справедливо и то, что в условиях отсутствия какого-либо алгоритма разграничения вопросов факта и права эффективность использования этой концепции падает, а задача разрешения пограничных вопросов выполняется правоприменителем ad hoc (в рамках разрешения конкретного вопроса и спора), что не всегда обеспечивает консистентность принимаемых решений. Более четкое понимание причин и порядка разграничения вопросов факта и права в юриспруденции необходимо для дальнейшего совершения правовых институтов, в которых это разграничение проявляется. Когда отделению вопросов факта от вопросов права дается больше внимания, процесс правоприменения и выработки правовой позиции становится понятнее, логичнее, предсказуемее как для участников правоприменительного процесса, так и для правоприменителя.

Подготовлено при информаџионной поддержке СПС КонсультантПлюс.

${ }^{1}$ См.: Определение Верховного Суда Российской Федерации №30-КГ20-1-К5. Банк судебных решений. URL: http://vsrf.ru/stor_pdf.php?id=1905686.html (дата обращения 16.01.2021г.). 


\section{Список литературы}

1. Абова Т.Е., Богуславский М.М., Светланов А.Г. 2005. Комментарий к Гражданскому кодексу Российской Федерации. М., Издательство Юрайт, 1069 с.

2. Будылин С.Л. 2014. Вопрос права или вопрос факта? Доказывание и кассация. Вестник ФАС Уральского округа, 2 (30): 79-124.

3. Гурвич М.А. 1976. Судебное решение: Теоретические проблемы. М., Юридичсекая литература, $175 \mathrm{c}$.

4. Елисеев Н.Г. 2004. Гражданское процессуальное право зарубежных стран. М., Проспект, $602 \mathrm{c}$.

5. Казанский П. 1902. Учебник международного права публичного и гражданского. Одесса, «Экон.» тип., 532 с.

6. Макогон Б.В. 2014. Компонент юридической ответственности в процессуальноограничительной деятельности публичных властных субъектов. Наука и образование: хозяйство и экономика; предпринимательство; право и управление, 6 (49): 74-80.

7. Макогон Б.В. 2017. Методологически опорная трактовка юридического процесса. Наука и образование: хозяйство и экономика; предпринимательство; право и управление, 1 (80): 32-35.

8. Макогон Б.В. 2013. Процессуально-правовые ограничения как атрибут деятельности властных субъектов. Монография. Москва, Издательский дом «Юр-ВАК», 207 с.

9. Попаденко Е.В., Красильникова Е.В. 2019. Суд присяжных. М, Юрайт, 169 с.

10. Яблочков Т.М. 1909. Курс международного гражданского процессуального права. Ярославль: Типография Губернского Правления. 212 с.

11. Casey K., Camara J., Wright N. 2001. Standards of Appellate Review in the Federal Circuit: Substance and Semantics. Federal Circuit Bar Journal, Vol. 11: 1-83.

12. Coke E. 1832. The First Part of the Institutes of the Laws of England; or, a Commentary upon Littleton. 19th ed. Vol. 1. London. $788 \mathrm{p}$.

13. Diane Vaksdal Smith. 2006. Finality of Judgment: Issue Preclusion, Claim Preclusion, and Law of the Case. The Colorado Lawyer. July. URL: https://www.researchgate.net/publication/242782015_Finality_of_Judgment_Issue_Preclusion_Claim_Pr eclusion_and_Law_of_the_Case (дата обращения 11.03.2021).

14. Friedenthal J.H., Kane M.K., Miller A.R. 1999. Civil procedure. Fourth Edition. Hornbook series. Thomson/West. 896.

15. Hausmann R. 2008. Pleading and Proof of Foreign Law - a Comparative Analysis. The European Legal Forum, № 1. I-1 - I-60.

16. Michalski R. 2011. Pleading and Proving Foreign Law in the Age of Plausibility Pleading. Buffalo Law Review, Vol. 59: 1207-1266.

17. O’Brien J. 1999. Conflict of Laws. London. 652 p.

18. Weiner S.A. 1966. The Civil Jury Trial and the Law-Fact Distinction. California Law Review, Vol. 54: 1867-1940.

\section{References}

1. Abova T.E., Boguslavskij M.M., Svetlanov A.G. 2005. Kommentarij k Grazhdanskomu kodeksu Rossijskoj Federacii [Commentary to the Civil Code of the Russian Federation]. M., Publ. YUrajt. 1069.

2. Budylin S.L. 2014. Vopros prava ili vopros fakta? Dokazyvanie i kassaciya [A question of law or a question of fact? Proof and cassation]. Vestnik FAS Ural'skogo okruga, 2: 79-124. (In Russian)

3. Gurvich M.A. 1976. Sudebnoe reshenie: Teoreticheskie problem [Judicial decision: Theoretical problems]. M., Publ. YUridicheskaya literatura, $175 \mathrm{p}$.

4. Eliseev N.G. 2004. Grazhdanskoe processual'noe pravo zarubezhnyh stran [Civil procedural law of foreign countries]. M., Publ. Prospekt, 602 p.

5. Kazanskij P. 1902. Uchebnik mezhdunarodnogo prava publichnogo i grazhdanskogo [Textbook of International public and Civil law]. Odessa, Publ. «Ekon.» tip., 532 p.

6. Makogon B.V. 2014. Komponent yuridicheskoj otvetstvennosti v processual'no-ogranichitel'noj deyatel'nosti publichnyh vlastnyh sub"ektov [The component of legal responsibility in the procedural and 
restrictive activities of public authorities]. Nauka i obrazovanie: hozyajstvo i ekonomika; predprinimatel'stvo; pravo i upravlenie, 6 (49): 74-80.

7. Makogon B.V. 2017. Metodologicheski opornaya traktovka yuridicheskogo processa [Methodological reference interpretation of the legal process]. Nauka i obrazovanie: hozyajstvo i ekonomika; predprinimatel'stvo; pravo i upravlenie-1(80): 32-35. (In Russian)

8. Makogon B.V. 2013. Processual'no-pravovye ogranicheniya kak atribut deyatel'nosti vlastnyh sub"ektov. Monografiya [Procedural and legal restrictions as an attribute of the activities of power subjects. Monograph]. Moscow, Publ. "YUr-VAK". 207 p. $169 \mathrm{p}$.

9. Popadenko E.V., Krasil'nikova E.V. 2019. Sud prisyazhnyh [Trial by jury]. M., Publ. YUrajt.

10. YAblochkov T.M. 1909. Kurs mezhdunarodnogo grazhdanskogo processual'nogo prava [Course of International Civil Procedure Law]. Publ. YAroslavl': Tipografiya Gubernskogo Pravleniya. 212 p.

11.Casey K., Camara J., Wright N. 2001. Standards of Appellate Review in the Federal Circuit: Substance and Semantics. Federal Circuit Bar Journal, Vol. 11: 1-83.

12.Coke E. 1832. The First Part of the Institutes of the Laws of England; or, a Commentary upon Littleton. 19th ed. Vol. 1. London. 788 p.

13.Diane Vaksdal Smith. 2006. Finality of Judgment: Issue Preclusion, Claim Preclusion, and Law of the Case. The Colorado Lawyer. July. URL: https://www.researchgate.net/publication/242782015_Finality_of_Judgment_Issue_Preclusion_Claim_Pr eclusion_and_Law_of_the_Case (Date Accessed 11.03.2021).

14.Friedenthal J.H., Kane M.K., Miller A.R. 1999. Civil procedure. Fourth Edition. Hornbook series. Thomson/West. 896.

15.Hausmann R. 2008. Pleading and Proof of Foreign Law - a Comparative Analysis. The European Legal Forum, № 1: I-1 - I-60.

16. Michalski R. 2011. Pleading and Proving Foreign Law in the Age of Plausibility Pleading. Buffalo Law Review, Vol. 59: 1207-1266.

17.O'Brien J. 1999. Conflict of Laws. London. 652 p.

18. Weiner S.A. 1966. The Civil Jury Trial and the Law-Fact Distinction. California Law Review, Vol. 54: 1867-1940.

\section{ИНФОРМАЦИЯ ОБ АВТОРАХ}

Куксин Иван Николаевич, профессор, доктор юридических наук, профессор кафедры теории и истории государства и права Института права и управления Московского городского педагогического университета, г. Москва, Россия

Зеленин Никита Юрьевич, аспирант кафедры теории и истории государства и права Института права и управления Московского городского педагогического университета, г. Москва, Россия

\section{INFORMATION ABOUT THE AUTHORS}

Ivan N. Kuksin, Professor, Doctor of Law, Professor of the Department of Theory and History of State and Law, Institute of Law and Management, Moscow City Pedagogical University, Moscow, Russia

Nikita Y. Zelenin, PhD Student, Department of Theory and History of State and Law, Institute of Law and Management, Moscow City Pedagogical University, Moscow, Russia 